\title{
Does Bile Reflux Influence the Progression of Barrett's Esophagus to Adenocarcinoma? (Gastroenterology 2013;145:1300-1311)
}

\section{Tatsuhiro Masaoka and Hidekazu Suzuki*}

Division of Gastroenterology and Hepatology, Department of Internal Medicine, Keio University School of Medicine, Tokyo, Japan

\section{Summary}

In recent times, the incidence of esophageal adenocarcinoma (EAC) in Western countries is increasing. Barrett's esophagus (BE) is characterized by the replacement of the squamous epithelium by metaplastic columnar epithelium in the lower esophagus. It is a premalignant lesion that is detected in a majority of patients with EAC. Gastroesophageal reflux disease (GERD) and bile reflux are known to cause $\mathrm{BE}$ and $\mathrm{EAC}$. Caudal-related homologue 2 (CDX2), is a homeodomain transcription factor that regulates normal intestinal cell differentiation by functioning as a tumor suppressor protein, and its expression levels are associated with the prognosis of adenocarcinomas. Moreover, decreased levels of $\mathrm{CDX} 2$ are reported during the progression of $\mathrm{BE}$ to metaplasia, dysplasia and EAC. ${ }^{2}$ However, little is known about the molecular mechanism that downregulates CDX2 in the carcinogenesis of $\mathrm{BE}$. The inhibitor p27Kip1, a member of the $\mathrm{Cip} / \mathrm{Kip}$ family of cyclin-dependent kinase (CDK) inhibitors has been reported to stabilize CDX2 protein by blocking its phosphorylation and degradation. ${ }^{3}$

Matsuzaki et $\mathrm{al}^{4}$ designed this study to investigate whether bile acids affect the expression of microR NA-221 and microRNA-222 (miR-221 and miR-222), which bind to p27Kip1 mRNA and facilitate the degradation of CDX2 in the esophagus.

In the biopsy samples of $\mathrm{BE}$ and EAC, obtained from $11 \mathrm{pa}-$ tients, the levels of $m i R-221$ and $m i R-222$ were increased, as indicated by quantitative reverse transcriptase PCR, whereas the levels of p27Kip1 and CDX2 protein were decreased, as indicated by immunohistochemistry, in the areas of EAC when compared to areas of BE. Levels of $m i R-221$ and $m i R-222$ increased along with the activity of farnesoid $\mathrm{X}$ receptor (FXR) when EAC cells (OE33) or human esophageal squamous epithelial cells transfected with a CDX2 transgene (HET1A + $\mathrm{Cdx} 2$ ) were exposed to bile acids (cholic acids or chenodeoxycholic acid). When the cells were incubated with bile acids, the degradation of CDX2 increased. However, this process was attenuated when the cells were incubated with proteasome inhibitors. Overexpression of miR-221 and miR-222 reduced the levels of p27Kip1 and CDX2, whereas the knockdown of these miRNAs increased the levels of these proteins in the cultured cells. Inhibitors of miR-221 and miR-222 increased the levels of p27Kip1 and CDX2 in the EAC cells and reduced the growth of human EAC xenograft tumors in NOD/SCID/IL-2R $\gamma^{\text {null }}$ (NOG) mice. The degradation of CDX2 was enhanced by the

Received: September 25, 2013 Revised: November 19, 2013 Accepted: November 28, 2013

(c) This is an Open Access article distributed under the terms of the Creative Commons Attribution Non-Commercial License (http://creativecommons. org/licenses/by-nc/3.0) which permits unrestricted non-commercial use, distribution, and reproduction in any medium, provided the original work is properly cited.

*Correspondence: Hidekazu Suzuki, MD, PhD, FACG

Division of Gastroenterology and Hepatology, Department of Internal Medicine, Keio University School of Medicine, 35 Shinanomachi, Shinjuku-ku, Tokyo 160-8582, Japan

Financial support: None.

Tel: +81-3-5363-3790,Fax: +81-3-5363-3967, E-mail: hsuzuki@a6.keio.jp

Conflicts of interest: None. 
increased levels of $m i R-221$ and $m i R-222$ during exposure to bile acids via FXR activation in human esophageal epithelial cells. The findings of this study suggest that the FXR pathway could emerge as a therapeutic target and implicate the therapeutic potential of FXR antagonists or inhibitors of miRNAs as a treatment option for $\mathrm{BE}$ and $\mathrm{EAC}$.

\section{Comments}

Matsuzaki et $\mathrm{al}^{4}$ investigated for the first time the function and regulation of $m i R-221$ and $m i R-222$ in the BE and evaluated the effect of bile acids on the expression levels of $m i R-221$ and $m i R-222$. This article also showed the pathogenic mechanism responsible for the transformation of $\mathrm{BE}$ to $\mathrm{EAC}$ ranging from miR-221 and miR-222 to CDX2 and p27Kip1 expression.

The role of bile reflux in carcinogenesis is evolving. The $G$ protein-coupled bile acid receptor (TGR5) is a cell membranebound bile acid receptor. Bile acids are known to act through the nuclear receptor FXR or through TGR5. Matsuzaki et al ${ }^{4}$ evaluated the effect of both TGR5 agonist and the FXR agonist. The levels of $m i R-221$ and $m i R-222$ were increased during exposure to the FXR agonist, but not the TGR5 agonist. Moreover, the FXR agonist suppressed the expression of p27Kip1, and enhanced the degradation of CDX2, whereas the TGR5 agonist did not show such an effect. Recently, Guan et $\mathrm{al}^{5}$ reported that inhibition of FXR suppressed tumor cell viability and induced apoptosis in vitro, and it also reduced tumor formation and growth in nude mouse xenografts. Taken together, main role of FXR, not TGR5 in this mechanism was suggested.

When duodenal reflux was abolished in duodenal diversion operation, histologic regression of low-grade dysplasia to nondysplastic mucosa was observed and no progression to highgrade dysplasia or adenocarcinoma occurred. ${ }^{6}$ Recently, Zaika et $\mathrm{al}^{7}$ reported up-regulation of $\Delta \mathrm{Np} 73 \alpha$ protein, an inhibitor of p53 and p73 tumor suppressors in esophageal tissues collected from patients with GERD and BE. Moreover, they demonstrated that direct exposure of esophageal cells to bile acids in an acidic environment alters the phosphorylation of $\Delta \mathrm{Np} 73$, its subcellular localization and increases $\Delta \mathrm{Np} 73$ protein levels. ${ }^{7}$ These results suggest association between $\mathrm{EAC}$ and bile reflux.

In normal esophageal squamous epithelia, CDX2 protein expression is absent while expression of $\mathrm{CDX} 2$ in $\mathrm{BE}$ was previously reported. ${ }^{8}$ In 2011, Hayes et $\mathrm{al}^{2}$ reported upregulation of CDX2 expression followed by linear down regulation through the esophageal metaplasia-dysplasia-adenocarcinoma sequence for the first time. This is consistent with what Matsuzaki et $\mathrm{al}^{4}$ reported. Recently, Makita et $\mathrm{al}^{9}$ also reported CDX2 expression in the non-neoplastic Barrett's esophageal mucosa while it was not found in low-grade to high-grade dysplasia and intramucosal adenocarcinoma. Recently, this sequence is acquiring consensus.

In order to prevent the progression of $\mathrm{BE}$ to $\mathrm{EAC}$, an endoscopic eradication therapy with radiofrequency ablation is used in Western countries. ${ }^{10}$ Endoscopic eradication significantly reduces the frequency of progression to esophageal cancer in $\mathrm{BE}$ patients with high-grade dysplasia. However, the efficacy of this therapy with low-grade dysplasia in BE is still unknown. Novel biomarkers are needed to detect high-risk BE patients with low-grade dysplasia who may eventually develop a progression to EAC. This study clarified the role of bile reflux in the progression of $\mathrm{BE}$ to EAC. Hence, BE patients with low-grade dysplasia associated with bile reflux should potentially be included in the high-risk group.

The prognosis of EAC is known to be poor. However, the therapeutic application of FXR antagonists or inhibitors of miRNAs have the potency to be beneficial for EAC or BE patients with high risk of developing EAC.

\section{References}

1. Matsuzaki J, Suzuki H, Asakura K, et al. Gallstones increase the prevalence of Barrett's esophagus. J Gastroenterol 2010;45:171-178.

2. Hayes S, Ahmed S, Clark P. Immunohistochemical assessment for $\mathrm{Cdx} 2$ expression in the Barrett metaplasia-dysplasia-adenocarcinoma sequence. J Clin Pathol 2011;64:110-113.

3. Boulanger J, Vézina A, Mongrain S, et al. Cdk2-dependent phosphorylation of homeobox transcription factor $\mathrm{CDX} 2$ regulates its nuclear translocation and proteasome-mediated degradation in human intestinal epithelial cells. J Biol Chem 2005;280:18095-18107.

4. Matsuzaki J, Suzuki $\mathrm{H}$, Tsugawa $\mathrm{H}$, et al. Bile acids increase levels of microRNAs 221 and 222, leading to degradation of CDX2 during esophageal carcinogenesis. Gastroenterology 2013;145:1300-1311.

5. Guan B, Li H, Yang Z, Hoque A, Xu X. Inhibition of farnesoid X receptor controls esophageal cancer cell growth in vitro and in nude mouse xenografts. Cancer 2013;119:1321-1329.

6. Csendes A, Smok G, Burdiles P, Braghetto I, Castro C, Korn O. Effect of duodenal diversion on low-grade dysplasia in patients with Barrett's esophagus: analysis of 37 patients. J Gastrointest Surg 2002;6:645-652.

7. Zaika E, Bhardwaj V, Wei J, et al. Proinflammatory cytokines and bile acids upregulate DeltaNp73 protein, an inhibitor of p53 and p73 tumor suppressors. PLoS One 2013;8:e64306.

8. Phillips RW, Frierson HF Jr, Moskaluk CA. Cdx2 as a marker of epithelial intestinal differentiation in the esophagus. Am J Surg Pathol 2003;27:1442-1447. 
9. Makita K, Kitazawa R, Semba S, et al. Cdx2 expression and its promoter methylation during metaplasia-dysplasia-carcinoma sequence in Barrett's esophagus. World J Gastroenterol 2013;19:536-541.
10. Spechler SJ. Barrett esophagus and risk of esophageal cancer: a clinical review. JAMA 2013;310:627-636. 